\title{
QUEEN'S
UNIVERSITY
BELFAST
}

\section{Assistive technology: Understanding the needs and experiences of individuals with autism spectrum disorder and/or intellectual disability in Ireland and the UK}

O'Neill, S. J., Smyth, S., Smeaton, A., \& O'Connor, N. E. (2019). Assistive technology: Understanding the needs and experiences of individuals with autism spectrum disorder and/or intellectual disability in Ireland and the UK. Assistive Technology. https://doi.org/10.1080/10400435.2018.1535526

Published in:

Assistive Technology

Document Version:

Peer reviewed version

Queen's University Belfast - Research Portal:

Link to publication record in Queen's University Belfast Research Portal

Publisher rights

Copyright 2019 T \& F. This work is made available online in accordance with the publisher's policies. Please refer to any applicable terms of use of the publisher.

\section{General rights}

Copyright for the publications made accessible via the Queen's University Belfast Research Portal is retained by the author(s) and / or other copyright owners and it is a condition of accessing these publications that users recognise and abide by the legal requirements associated with these rights.

Take down policy

The Research Portal is Queen's institutional repository that provides access to Queen's research output. Every effort has been made to ensure that content in the Research Portal does not infringe any person's rights, or applicable UK laws. If you discover content in the

Research Portal that you believe breaches copyright or violates any law, please contact openaccess@qub.ac.uk. 


\title{
Assistive technology: Understanding the needs and experiences of individuals with Autism Spectrum Disorder and/or Intellectual Disability in Ireland and the UK.
}

\author{
Sean J. O’Neill ${ }^{\mathrm{a}}$, Sinéad Smyth* a , Alan Smeaton ${ }^{\mathrm{b}} \&$ Noel E. O’Connor ${ }^{\mathrm{b}}$ \\ ${ }^{\text {a }}$ School of Nursing and Human Sciences \& \\ ${ }^{\mathrm{b}}$ Insight Centre for Data Analytics \\ Dublin City University, Ireland.
}

*Corresponding author: sinead.smyth@dcu.ie (S. Smyth). School of Nursing and Human Sciences, Dublin City University, Glasnevin, Dublin 9, Phone No. +353 1- 7007422.

\section{Acknowledgements}

This work was supported by funding from the People Programme (Marie Curie Actions) of the European Union's Seventh Framework Programme (FP7/2007-2013) and the charity RESPECT under REA grant agreement no. PCOFUND-GA-2013608728.

The authors would like to acknowledge the help of Lisa Domican, creator of Grace App, the charities RESPECT, and Parents' Education as Autism Therapists (PEAT) and to those that helped to circulate and share this survey. We would like to acknowledge the work of Cynthia Putnam and Lorna Chong for their contribution to this area of work. 


\begin{abstract}
Assistive technologies (ATs) aimed at improving the life quality of persons with Autism Spectrum Disorder and/or Intellectual Disability (ASD/ID) is an important research area. Few have examined how this population use and experience AT or their vision for future uses of AT. The present study aimed to update and extend previous research and provides insight from caregivers, and other stakeholders $(\mathrm{n}=96)$, living in Ireland and the United Kingdom, on their experiences of assistive technology (AT) for ASD/ID. Caregiver and professional responses to an anonymous online survey showed that focus-individuals were rated low in terms of independent and self-management skills, with scheduling and planning and communication identified as desirable future AT functions. Overall, positive experiences of AT were reported, with AT use more than doubling in recent years.
\end{abstract}

Keywords: Assistive Technology (AT), Autism Spectrum Disorder (ASD), Intellectual Disability (ID), self-management, smartphone, tablet 


\section{Introduction}

The World Health Organization (WHO) define Assistive Technology (AT) as: 'assistive products and related systems and services developed for people to maintain or improve functioning and thereby promote well-being' (WHO, 2016, p. 1). It can be more specifically defined as technology that is used on an on-going basis to support individuals to the completion of tasks, or instructional technology that is explicitly used to build skills (Ayres, Mechling, \& Sansosti, 2013). The technology employed may take any number of forms and significant technological progress in recent years in information and communications technology (ICT) have led to rapid advances in ICT based AT. This has included the development and adoption of ATs for use by persons with an Autism Spectrum Disorder (ASD) or Intellectual Disability (ID) (Ploog, Scharf, Nelson, \& Brooks, 2013). Publications in digital libraries related to technology for this population have gone from two in 2000 to a reported 66 per year in 2010 (Virnes, Kärnä, \& Vellonen, 2015). In addition, a recent cursory search of the Web of Science database using the term 'assistive technology*' show the number of publications to have increased upwardly over the past five years. In 2013 there were 399 publications; 550 in 2014; 648 in 2015; 744 in 2016; and 754 in 2017. This upward trend appears set to continue into the future by all accounts (Aresti-Bartolome \& Garcia-Zapirain, 2014; Raento, Oulasvirta, \& Eagle, 2009).

ASD is marked by deficits in social communication and interaction and is accompanied by repetitive and restrictive behaviors, activities and interests (American Psychiatric Association, 2013). These deficits can negatively impact life quality by hampering a person's ability to learn, build relationships and develop the skills necessary to function independently (Alwell \& Cobb, 2006). For this reason, it is particularly important that individuals with ASD/ID get the services most likely to produce optimal outcomes (Orinstein et al., 2014). However, within the Irish context, statutory service provision is 
limited; not all of those in need of support receive it (Keenan, Dillenburger, Doherty, Byrne, \& Gallagher, 2007). Although AT can be no substitute for direct service provision, it can, however, play an important adjunct role at improving the capabilities of individuals diagnosed as having an ASD/ID (Allen \& Shane, 2014). One result of this increased capability may be increased independence, minimizing the reliance placed on caregivers (Liu, Wu, \& Chen, 2013; Mechling, 2007). Indeed, AT is reported to be effective for individuals with an ASD/ID (Mechling \& Seid, 2011) and has also been shown to be motivating and preferred when compared with manual methods (Bouck, Savage, Meyer, Taber-Doughty, \& Hunley, 2014; Couper et al., 2014). Perhaps this 'good fit' is due in part to an over-reliance on routines, and preference for sameness that is demonstrated so often by individuals from this group, a proclivity that matches well with the predictability offered by ATs (Mechling, 2007; Putnam \& Chong, 2008). Whatever the cause, ATs have served many functions to the benefit of these individuals, including teaching sight word reading (Mechling, Gast, \& Krupa, 2007); teaching mathematics using iPads (Burton, Anderson, Prater, \& Dyches, 2013); building social skills (Parsons \& Cobb, 2011); improving scheduling using tablet devices (Fage, Pommereau, Consel, Balland, \& Sauzéon, 2014); and using mobile AT for instructional purposes and for the purpose of supporting on-going day-to-day task completion (Ayres et al., 2013). This list is not exhaustive; however, these examples do demonstrate the assorted applications of AT used for individuals with an ASD/ID.

A first step towards utilizing AT fully is to better understand the experiences of those that have engaged with it. Stakeholder and end-user involvement is recognized as being crucial in the development of AT; however, engagement from end-users with an ASD/ID does present its challenges, particularly if communication is hindered, as is often the case in this group (De Leo \& Leroy, 2008). Researchers and AT designers are in need of detailed feedback from those that have interacted with it. With this in mind, it is clear that parents, 
guardians, friends, and professionals working closely with, or caring for, children or young adults with these diagnoses are well positioned to advocate for this group. Soliciting the views of a proxy respondent is not novel (Becerra et al., 2017; Lai \& Weiss, 2017; Putnam \& Chong, 2008), nor is it preferred; however, it allows for important feedback for researchers should it not be possible, for pragmatic reasons, to sample ASD/ID users directly.

Indeed, Putnam and Chong conducted a study in 2008 which evaluated what individuals with an ASD wanted from software technologies and how this technology was integrated into their lives. They used an online survey that asked adults with ASD, and their caregivers, questions that related to their experience of AT, and how these experiences could be improved. One noteworthy finding was that despite the increased availability of AT at the time, only $25 \%$ of their sample group had any experience of using it. Interestingly, those that had experience of using AT reported it as being a positive one, having mainly accessed software using a personal computer. Furthermore, their sample reported positive attitudes toward technology-related interventions in general and specifically identified social/communication, academic/school help, and scheduling/organization as highly desirable functions of AT for the future. AT that involved smartphones was not discussed by Putnam and Chong; although a 'cellphone' option existed within their survey when asking respondents to identify AT devices they had used. Presumably, this was due to respondents not having identified it as a form of AT that they had experience with. This outcome is hardly surprising given that the first smartphone was introduced to the market in 2007, to be followed by the iPad in 2010. These developments have re-shaped the ICT landscape, and have resulted in mobile technologies being used more and more to support users with ASD/ID in various contexts (Ayres et al., 2013; De Leo \& Leroy, 2008; McDowell, Hardy, \& Smyth, 2017; Mintz, 2013). Clearly, there have been significant developments in mobile technologies and their capabilities since 2008. These developments and their implications for 
individuals with ASD/ID have largely not been examined in the research literature. It, therefore, seems timely to investigate how AT, and especially AT accessed via smartphone devices, is being used by individuals with ASD/ID, how this AT is rated, and what future direction AT should take.

In 2013, smartphone diffusion was reported to be the latest widespread technology dispersion underway, with penetration of smartphones, in the highest cluster of countries, reported to be between 60-70\%, a significant increase since 2011 (Kakihara, 2014). Additionally, research by the Pew Research Centre reports that $64 \%$ of American adults in 2014 own a smartphone, an increase from 35\% in 2011 (Smith, McGeeney, Duggan, Rainie, \& Keeter, 2015). It is probable that the increased functionality of smartphones has, in part, fueled their widespread proliferation. Today smartphone technology, and its sensor capabilities (e.g., GPS, accelerometer, microphone, touch screen, and camera), may represent a form of AT that is affordable, adaptable, and compatible with many off the shelf applications (e.g., 'apps'). Most importantly, these forms of AT may be accessed by individuals in public very discreetly (Ayres et al., 2013). Most typically developing individuals engage with their smartphone or tablet devices in public and throughout the day. This ubiquitous use, and normalization of technology used publically, offer individuals with ASD/ID the opportunity to engage with AT without being stigmatized. This feature leverages a significant advantage over other forms of AT and is particularly important given that individuals with ASD/ID are reported to be at an increased risk of victimization and bullying (Sreckovic, Brunsting, \& Able, 2014).

It is timely that we now investigate how to better leverage AT in an evaluation of the support needs, experiences, and expectations of ASD/ID users. While limited previous research has attempted to uncover uptake of, and experiences of AT, the ICT landscape, particularly with regard to mobile technology, is changing. The present study provides an 
updated overview of AT as used by individuals with ASD. This overview was provided by surveying those in a position to advocate for this group; parents, caregivers, guardians, friends, and professionals. It extends previous work (Putnam \& Chong, 2008) by including views related to individuals with ID. Although all forms of AT were addressed by this survey, smartphone technologies were given an increased focus. The present study surveyed the experiences of parents, caregivers, guardians, friends and professionals of individuals with an ASD/ID and sought to understand the following: (a) demographic information on focus-individuals and type of service they accessed; (b) what level of support needs do individuals with ASD/ID have; (c) how AT is being used or has been used, and how this experience was rated; and (d) what future role AT should play for this group. Survey questions are included in Appendix A.

\section{Method}

\section{Respondent submissions}

Parents, guardians, friends, and professionals working with, or caring for, children or young adults with a diagnosis of ASD/ID responded to the current survey. These respondents acted as proxies for individuals with ASD/ID. Each respondent was instructed to answer the survey questions related to one individual with ASD/ID and to complete a separate survey for additional focus-individuals.

\section{Distribution}

The present study was approved for distribution by Dublin City University's Research and Ethical Review Committee. The survey used a snowball sampling technique for distribution. A covering letter that contained a description of the study and hyperlink to the survey was emailed to various non-profit and charitable organizations located in Ireland and the UK. This survey subsequently was distributed by these groups using a combination of methods, they included: one electronic mailing list consisting of approx. 200 recipients; 
posting on social media pages (Facebook and Twitter) and websites; and being printed in one organization's newsletter. The survey remained open for approximately 2.5 -months.

\section{Materials}

Qualtrics $^{\mathrm{TM}}$ is the online research tool that was used to create the questionnaire and survey stakeholder experiences of AT as related to individuals with ASD/ID. The online questionnaire consisted of 23 items, shown in Appendix A. These included open and closeended questions with a variety of response modes (i.e., Likert-type scales) that allowed respondents to rate concepts based on these experiences. Post-distribution, two questions were excluded from analysis as no meaningful responses could be obtained (Q22, Q23). A branching design was incorporated into this questionnaire. This allowed for a participant response to determine subsequent questions that were then presented. This feature avoided participants spending unnecessary time completing irrelevant questions.

The online survey contained an initial page that provided background information to the study (e.g., the purpose of the study, anonymity afforded, informed consent information, and confirmation of age 18+ years). Following this, a number of questions were presented to respondents, they included:

\section{Information on the focus-individual and service access}

This section asked close-ended questions related to demographic information (Q1-3, Appendix A; diagnosis, age, and gender) and the nature of the relationship between the respondent and the focus-individual (Q4, Appendix A). This section also sought information on what type of services (e.g., residential or community), if any, the focus-individual had access to.

\section{Support/independence level of individuals with ASD/ID}

This part of the survey asked questions that related to the type of service supports focus-individuals were able to access and their rated level of independence. They included: 
rated level of support needed to manage their time and daily activities, rated level of selfmanagement skills and rated level of independence (Q5-8, Appendix A). Additionally, an open-ended question asked: what the biggest barrier to independence was for the focus individual (Q9, Appendix A).

\section{Current and past experiences of AT}

This section included questions relating to past and current AT use, they included: whether or not focus individuals currently used or had experience with AT (a definition of AT was included (Q10, Appendix A), what number of ATs were used or in use, the purpose of this AT, and what kind of device was used to access the AT (Q11-13, Appendix A). Respondents were then asked to rate these experiences of AT using a number of dimensions (Q14; e.g., effectiveness, ease of use, needs driven, accessible, cost effectiveness; see Table 1).

\section{Future role of AT for persons with ASD/ID}

Here respondents were asked questions that focused on the desirable future role of AT and probed openness to smartphone devices used as an AT. An open-ended question (Q15) then asked: what improvements they would make to this AT if they were on the design team? Additional questions asked: whether or not the focus-individual had access to a smartphone; their rated ability to use a smartphone; the main purpose of the smartphone; how strongly respondents agreed/disagreed with the statement "Today smartphones are integrated with most people's daily lives"; whether the parent/guardian/caregiver had experience of using a smartphone; and what areas they believed would benefit most from a behavioural intervention that used smartphone technology (Q16-21, Appendix A).

Data analysis

Data were exported from Qualtrics ${ }^{\mathrm{TM}}$ into a statistical software package $\left(\mathrm{SPSS}^{\circledR}\right.$ ) for analysis. Descriptive statistics, including frequency, mean, and percentage calculations, were 
generated for responses made to close-ended questions (i.e., Q1-8, Q10-14, Q16-21, Appendix A). This was done using a stepped process. Step 1 involved the first author becoming familiar with the data set and generating initial codes made to responses to openended questions. At this step, the researcher would define and name the themes for each code. For example, responses such as "verbal ability", "speech", or "speaking" in response to a question on barriers to independence were coded collectively as communication barriers. This process was iterative in that initial codes could subsequently be changed if it was agreed that a more representative code could be found. Once responses had been initially generated, Step 2 involved refinement of codes and themes was undertaken by a second researcher. During Step 3, confirmation of agreement of the codes used between the first and second researcher was undertaken, and production of the output was finalized.

\section{Results}

Respondent submissions and geographic location

In total, 135 responses to the survey were commenced and of these, 107 were completed. A total of 11 completed surveys were excluded as they originated from outside of Ireland and the UK. Ninety-six individual survey submissions remained and were included in the final analysis. Respondent geographical locations were limited to Ireland and the United Kingdom $(\mathrm{UK})$ : $64 \%(\mathrm{n}=61)$ were from Ireland; $19 \%(\mathrm{n}=18)$ were from Northern Ireland $(\mathrm{UK}) ; 14 \%(\mathrm{n}=13)$ came from England (UK); 4\% $(\mathrm{n}=4)$ were from Wales (UK).

\section{Information on the focus-individual and service access}

From survey submissions, 54\% came from parents, guardians, and caregivers; $17 \%$ were from therapists; followed by $10 \%$ of teachers, $9 \%$ of respondents self-identified as 'other', and $6 \%$ self-identified as friend; $4 \%$ of respondents were other family members (e.g., cousin, uncle, aunt). The sample was dominated by reports relating to males ( $83 \%)$ with ASD/ID compared to $17 \%$ of females. The mean age grouping of focus individuals was 11 - 
14 years $(\mathrm{M}=3.20, \mathrm{SD}=1.75)$. Figure 1 illustrates age grouping according to diagnosis $(\mathrm{Q} 1$ -

2, Appendix A). This section also asked respondents what type of service provision focusindividuals with ASD/ID had access to (Q5, Appendix A). Thirty-three percent of focusindividuals received services within the community; $12 \%$ received residential services; $39 \%$ were unable to access services. Sixteen percent selected 'other' forms of services, these included privately paid for services, home services, and some respite.

\section{Support/independence level of individuals with ASD/ID}

When asked how much help/support focus-individuals need to manage their time or day-to-day activities; $26 \%$ of respondents reported them as requiring full support; $48 \%$ reported them as requiring a lot of support; with $21 \%$ reporting the focus individual as needing some support; $5 \%$ reported a little support needed; $1 \%$ reported no support needed. Focus individuals received a combined $73 \%$ rating of very low and low levels of independence. As a follow-up question, respondents were asked to rate the self-management level of the focus individual. Thirty-seven percent of respondents rated self-management level as very low; $42 \%$ rated it as low; with $17 \%$ rating it as neither high nor low; only $4 \%$ rated it as high. The top four barriers to independence included communication deficits, followed by a lack of service provision and resources, deficits in self-management skills, and joint fourth were cognitive ability and social skills.

\section{Current and past experiences of AT}

Fifty-eight percent $(n=45)$ responded 'yes' when asked whether or not the person this survey related to had used or was currently using a form of AT. Of this $58 \%, 49 \%$ reported using one form of AT; $36 \%$ reported using two forms of AT; $11 \%$ reported having used three forms; and, $5 \%$ reported having used five or more forms of AT. Further analysis shows that $30 \%$ of respondents used AT that served two or more functions and may be related to advancements in ICT, and a demand for AT to serve multiple functions. Respondents then 
reported that $32 \%$ of focus-individuals accessed AT using a tablet device; $9 \%$ used a computer; $8 \%$ used a smartphone; $4 \%$ used an augmentative communication device and $2 \%$ used a wearable; $2 \%$ selected 'other'.

We then probed the focus of these experiences with AT. As mentioned, ATs often served multiple functions, therefore respondents could select multiple functions when completing this part of the survey. An education function was selected by $31 \%$ of respondents; communication was selected by $25 \%$; challenging behavior was the focus of $16 \%$; scheduling and planning was selected by $15 \% ; 10 \%$ selected social skills; $2 \%$ selected recording behavior and 'other', respectively. We then asked respondents to rate these experiences with AT on a number of dimensions; effectiveness; ease of use; needs driven; accessibility; and cost effectiveness. Respondent percentage mean ratings of experiences with ATs were as follows: $38 \%$ rated their experience with AT as very good; $43 \%$ rated their experience as good; $14 \%$ rated it as fair; and 5\% rated it as poor. Mean rated experiences of AT was therefore reported as positive (38\% very good; $43 \%$ good; $14 \%$ fair; $5 \%$ poor). However, ratings related to cost effectiveness scored lowest relative to other experience related dimensions (see Table 1). When asked to rate how strongly they agreed or disagreed with the statement: 'Today smartphones are integrated with most people's daily lives', 84\% of respondents either strongly agreed or agreed. Additionally, 52\% of respondents reported that focus-individuals had access to a smartphone; $44 \%$ reported no access; $4 \%$ were unsure. Respondents were also asked to rate the ability focus-individual to use a smartphone. Fortyfour percent were reported as very good; $22 \%$ were reported as good; $25 \%$ were neither good nor bad; and $8 \%$ were reported as bad. Ninety-one percent of caregivers of persons with ASD/ID were reported as having experience of using a smartphone. This represents a sizeable group of individuals with ASD/ID, and their caregivers, that have access and experience of using a smartphone. Twenty-two percent of respondents reported that focus- 
individuals' used their smartphone for gaming; $17 \%$ reported use categorized as 'other'; $12 \%$ used it for making phone calls; $12 \%$ used their smartphone for texting; $5 \%$ used the calendar function on their smartphone; and, 5\% used the smartphone for video calls/FaceTime. For the respondents that had categorized their use of the smartphone as 'other', we then asked them to elaborate by listing some of these functions. These included: YouTube, the Grace App for Autism (non-speaking picture exchange communication system), and listening to music and reading.

Future role of AT for persons with ASD/ID

When respondents were asked, 'If you were on the design team, what would this AT be able to do for the person with ASD/ID that it currently does not, or did not do?', a number of desired future AT functions emerged. Twenty-two percent of respondents identified scheduling and planning; 19\% identified communication; 17\% identified increased accessibility; $11 \%$ reported skills training as a desirable feature; with $14 \%$ stating they were 'unsure'; $8 \%$ identified personalization; and $8 \%$ social skills. Some stated that they would like to see an app that prompted behaviors that included 'getting up, eating and exercising', others desired an app that 'did activity scheduling' and 'planning/scheduling'. Responses to this question demonstrate a high preference for AT that enable persons with ASD/ID greater independence throughout their day.

Finally, respondents were asked what areas would benefit most from a behavioral intervention that used smartphone technology? Communication was selected $57 \%$ of the time; scheduling and planning daily events and activities was selected by $52 \%$ of respondents; $47 \%$ selected an educational function; $46 \%$ selected social skills; $40 \%$ selected behavioral improvement; and 6\% selected 'other'. Money management and speech and language were identified as desirable future roles for AT by one respondent that had selected 'other'. 


\section{Discussion}

Understanding the AT requirements of individuals with ASD/ID in Ireland and the UK will enable researchers and practitioners working in those jurisdictions to better meet those needs. The current survey updated and extended the work by Putnam and Chong (2008) by reporting on individuals with ASD, as well as those with ID. The largest group of respondents were from parents, guardians, and caregivers (54\%), followed by professionals (27\%), and was dominated by reports relating to males (83\%) as compared with females (17\%). Although this survey addressed all forms of AT, it gave particular focus to smartphone technology as a novel form of AT. Additionally, this study aimed to provide an updated understanding of the support needs and services accessed by individuals with ASD/ID, reported on here, current and past experiences of AT, and what future role AT should fulfill for this group.

Support/independence level of individuals with ASD/ID

Before we consider the future AT needs of individuals with ASD/ID, it seems important to contextualize this discussion within the current rated level of independence and self-management of users, as well as their access to supports and services. Respondents to the current survey reported level of independence and self-management skills of focusindividuals to be rated as either very low and low, whilst also reporting a high level of support to be needed to manage day-to-day activities. Communication was ranked highest in terms of barriers to independence to be followed by service provision and resources, selfmanagement skills, and cognitive ability and social skills, respectively. Much research activity in AT is already focused on communication (40.5\%) and education (37.8\%) (ArestiBartolome \& Garcia-Zapirain, 2014). Although this work is to be welcomed and should continue, research aimed at uncovering how best AT could be used to improve the self- 
management skills of this group is needed. This is an important line of future research given the frequency this set of skills is reported to be in deficit here, and the potential for improved self-management skills as providing the potential for a greater degree of independence for individuals from this group (Mechling, 2007). It should be noted that the questions in this section were designed to gain a broad view of focus-individuals level of independence, as reported by respondents, and is not an exhaustive measure.

Previous research has reported that parents and caregivers of children with ASD/ID are disproportionately at risk of experiencing increased stress and are more susceptible to negative and adverse family outcomes than parents of children with other disabilities (Dunn, Burbine, Bowers, \& Tantleff-Dunn, 2001; Vohra, Madhavan, Sambamoorthi, \& St Peter, 2013). Limited or absent statutory service provision and resources is only likely to exacerbate these negative effects and increase the barriers encountered by these families. Although Allen and Shane (2014) acknowledge the difficulty these negative and adverse experiences have for families; they also suggest that mobile technologies, used as AT, provide an opportunity to support persons with ASD/ID gain and increase in their daily independence. Therefore, the combination of mobile forms of ATs and self-management interventions are a good match and could be used to benefit end-users greatly.

\section{Current and past experiences of AT}

The current findings show an increase in the percentage of individuals with ASD/ID that are now accessing AT than was reported in the literature previously (Putnam \& Chong, 2008). Some $58 \%$ of respondents to this survey reported having experienced AT; more than double the $25 \%$ reported by Putnam and Chong. This increase has coincided with an increase in the number of AT devices, and accompanying apps available to ASD/ID users in the years since 2008. Thirty percent of respondents reported using AT that served two or more functions and may be indicative of recent advancements in ICT based AT, and a demand 
from users for technology that does more than one thing. This multi-functionality is a positive development for those that use AT and is also one that is likely to continue.

Perhaps unsurprisingly, the current findings support the observed changing ICT landscape and increased uptake in the use of mobile forms of AT. The majority (32\%) of respondents to the present survey reported accessing AT using a tablet device; $9 \%$ used a personal computer; with $8 \%$ using a smartphone. Previous research shows that respondents had mostly reported using a personal computer to access AT; 'cell phones' were not previously reported as having been used (Putnam \& Chong, 2008). Findings here suggest that the use of personal computers to access AT has declined with advancements in mobile forms of ICT based AT. These advancements have increased the availability, use of, and capabilities of both tablet devices and to a lesser degree, smartphones. While smartphones may appear underused given their proliferation in the general population, this may be due to the fact that they are a relatively new technology to have emerged as an AT device; or perhaps is less preferred given the larger screen and greater ease of interaction and accessibility offered by tablet devices. Although we cannot state that smartphone uptake as an AT has increased since the Putnam and Chong (2008) paper. Data here does show personal computer use and smartphone use, as an AT, to be closely matched. It is therefore plausible, given the increased diffusion and penetration of smartphones in many developed and developing countries (Kakihara, 2014), that smartphone devices may be increasingly used as an AT in the future. To demonstrate this point further, $84 \%$ of respondents to this survey agreed and strongly agreed with the statement "today smartphones are integrated with most people's daily lives". This finding illustrates the potential of the smartphone device as an emerging social, educational and behavioral health research tool (Boulos, Wheeler, Tavares, \& Jones, 2011; Dallery, Kurti, \& Erb, 2014; Mulvaney et al., 2013; Raento et al., 2009). Interestingly, however, this is higher than the $52 \%$ reporting to have access to 
smartphones in the current study, and in stark contrast with the $8 \%$ who use smartphones in an AT capacity. Apart from such issues as the capabilities and age of the focus-individuals reported on here, these gaps may indicate a potential for growth in the development of smartphone AT or could simply indicate a gap between perceived and actual smartphone use. Whatever the reason, one significant advantage of using a smartphone device as part of an intervention is its portability. This makes possible the passive recording of data through the smartphones many in-built sensors. In addition, the ability to prompt behavior change by integrating sensor and messaging, or notification capabilities, of the smartphone is a proposition to be realized further, and one that holds great opportunity for individuals with ASD/ID (Lathia et al., 2013).

Future role of AT for persons with ASD/ID

Scheduling and planning was rated highest in terms of desired future function of AT when probing respondent experiences of AT to this survey. Previous research has shown that when combined, AT and self-management strategies may improve the management of behaviors associated with a condition. For example, a study conducted by Hidalgo-Mazzei et al. (2015) reported on the development of an app, accessed using a smartphone, which monitored symptoms of bipolar depression. This app provided psycho-educational content and the ability to self-monitor the condition between therapy sessions in a cost-effective way. In addition, a study by Chuah and Diblasio (2012) reported on the development of an app that used a smartphone and wearable sensor to detect location and the engagement in stereotypical repetitive movements of individuals with ASD. The app then highlighted where and when these socially stigmatizing behaviors were more likely to occur; information that would allow for these behaviors to be managed better.

When respondents were asked what area(s) would benefit most from a combined behavioural intervention (i.e., based on the principles of Applied Behavioural Analysis; 
ABA) that used smartphone technology. A high proportion identified communication and scheduling and planning as areas that could benefit most from this kind of intervention. This suggests a demand for a combined intervention that use a smartphone device. Although communication as a desired focus of AT is a high priority for respondents to this survey, and elsewhere (Pituch et al., 2011), smartphone based AT designed to support scheduling and planning behaviors is identified as an emerging priority and one that is closely ranked with communication.

Interestingly, when comparing respondent reports of the current use of AT versus envisioned future use, some similarities and differences become evident. Education, communication, challenging behavior and scheduling and planning were identified as the top four current functions of AT; whereas, scheduling and planning, and communication were ranked first and second, respectively, in terms of desired future AT function. This data suggests two things; (1) that communication is consistently ranked by respondents as a priority in terms of current and future AT functionality, and (2) although scheduling and planning was ranked fourth in terms of current AT function, it appears to have now emerged to be a priority in terms of desired future AT function. Education was not identified as a priority future function of AT, an outcome that may be due to already widely available educationally focused AT (Aresti-Bartolome \& Garcia-Zapirain, 2014). In support of this trend, responses to open-ended questions reported that 'having an app that could prompt certain behaviors such as getting up, eating and exercising' as desirable. Others reported 'activity scheduling' and 'planning/scheduling' as desirable AT functions also. These verbal reports support the emerging theme of scheduling and planning behaviors, critical components of effective self-management, becoming a caregiver priority for AT function.

The current survey then sought to assess how feasible it would be to integrate a smartphone-based intervention into focus-individuals daily life. Some $52 \%$ of respondents 
reported that focus-individuals did have access to a smartphone, which represents a sizeable group of individuals with ASD/ID that may stand to benefit from this type of intervention. Furthermore, some $44 \%$ and $22 \%$ of respondents reported focus-individual use of smartphones to be very good and good, respectively. With $92 \%$ of caregivers from this group being familiar with using a smartphone, its acceptance as part of an intervention is likely to be high, which Delarosa et al. (2012) have shown to be a critical factor to the success of an AT involved intervention.

\section{Limitations}

It is, however, important to recognize the limitations of this study in terms of sampling method, size, and the representativeness of the sample. The sampling method used to gain 96 respondents was by its very nature, convenient, and may not be representative of the wider ASD/ID population. The findings reported on here should be understood as representing the views and experiences of those that responded to this survey. Any generalization of findings to the larger ASD/ID population should be done with caution. Future studies could examine further the level of support needed or independence level of individuals with ASD/ID, this could involve direct involvement of a greater number of respondents from this group, and from proxy respondents also.

\section{Conclusions}

In conclusion, respondents to this survey confirmed that focus-individuals with ASD/ID are in need of increased support across daily life with many unable to access supportive statutory services and resources. Data here also demonstrates an increase in the use of AT, with levels more than double those reported by Putnam \& Chong (2008). When we compare desired AT function with current AT function, scheduling and planning emerged as a high priority for respondents. Communication focused AT is consistently reported to be a high priority and may be related to this being a core deficit of ASD. Mobile forms of AT, 
such as tablet and smartphone devices, are particularly powerful forms of technology that may be used to support the development of scheduling and planning and communication skills. As noted, research, ongoing in both the behavioral and computing sciences, is focused on developing interventions that incorporate ICT based AT with behavioral science towards an individualized adjunct intervention (Chuah \& Diblasio, 2012; Dallery et al., 2014;

Hidalgo-Mazzei et al., 2015). These interventions are low cost, individualized and may help support individuals between therapy sessions. There are great successes to be realized by combining these areas but a job of work in terms of their objective empirical evaluation is still needed.

\section{Compliance with Ethical Standards}

This study was funded by the People Programme (Marie Curie Actions) of the European Union's Seventh Framework Programme (FP7/2007-2013) and the charity RESPECT under REA grant agreement no. PCOFUND-GA-2013-608728. Author A declares no conflict of interest. Author B declares no conflict of interest. Author C declares no conflict of interest. Author D declares no conflict of interest. This study was conducted in accordance with full ethical approval granted by Dublin City University’s research ethics committee.

\section{References}

Allen, A. A., \& Shane, H. C. (2014). Autism spectrum disorders in the era of mobile technologies : Impact on caregivers on caregivers. Journal of Developmental Neurorehabilitation, 17(2), 110-114. http://doi.org/10.3109/17518423.2014.882425

Alwell, M., \& Cobb, B. (2006). A systematic review of the effects of curricular interventions on the acquisition of functional life skills by youth with disabilities. Career Development for Exceptional Individuals, 29, 3-36.

American Psychiatric Association. (2013). Diagnostic and statistical manual of mental 
disorders (Fifth). Arlington, VA: American Psychiatric Publishing.

Aresti-Bartolome, N., \& Garcia-Zapirain, B. (2014). Technologies as support tools for persons with autistic spectrum disorder: A systematic review. International Journal of Environmental Research and Public Health, 11(8), 7767-7802. http://doi.org/10.3390/ijerph110807767

Ayres, K. M., Mechling, L. C., \& Sansosti, F. J. (2013). The use of mobile technologies to assist with life skills/independence of students with moderate/severe intellectual disability and/or autism spectrum disorders: Considerations for the future of school psychology. Psychology in the Schools, 50(3), 259-271. http://doi.org/doi.org/10.1002/pits.21673

Becerra, T. A., Massolo, M. L., Yau, V. M., Owen-Smith, A. A., Lynch, F. L., Crawford, P. M., ... Croen, L. A. (2017). A Survey of Parents with Children on the Autism Spectrum: Experience with Services and Treatments. The Permanente Journal/Perm J, 21, 16-9. http://doi.org/10.7812/TPP/16-009

Bouck, E. C., Savage, M., Meyer, N. K., Taber-Doughty, T., \& Hunley, M. (2014). HighTech or Low-Tech? Comparing Self-Monitoring Systems to Increase Task Independence for Students With Autism. Focus on Autism and Other Developmental Disabilities , 29(3), 156-167. http://doi.org/10.1177/1088357614528797

Boulos, M. N. K., Wheeler, S., Tavares, C., \& Jones, R. (2011). How smartphones are changing the face of mobile and participatory healthcare: an overview, with example from eCAALYX. Biomedical Engineering Online, 10, 24. http://doi.org/10.1186/1475925X-10-24

Braun, V., \& Clarke, V. (2006). Using thematic analysis in psychology. Qualitative Research in Psychology, 3(May 2015), 77-101. http://doi.org/10.1191/1478088706qp063oa

Burton, C. E., Anderson, D. H., Prater, M. a., \& Dyches, T. T. (2013). Video self-modeling 
on an iPad to teach functional math skills to adolescents with autism and intellectual disability. Focus on Autism and Other Developmental Disabilities, 28(2), 67-77. http://doi.org/10.1177/1088357613478829

Chuah, M., \& Diblasio, M. (2012). Smartphone based autism social alert system. Proceedings - 2012 8th International Conference on Mobile Ad Hoc and Sensor Networks, MSN 2012, 6-13. http://doi.org/10.1109/MSN.2012.41

Couper, L., Van Der Meer, L., Schäfer, M. C. M., McKenzie, E., McLay, L., O’Reilly, M. F., ... Sutherland, D. (2014). Comparing acquisition of and preference for manual signs, picture exchange, and speech-generating devices in nine children with autism spectrum disorder. Developmental Neurorehabilitation, 17(2), 99-109. http://doi.org/10.3109/17518423.2013.870244

Dallery, J., Kurti, A., \& Erb, P. (2014). A new frontier: Integrating behavioral and digital technology to promote health behavior. The Behavior Analyst, 38(1), 19-49. http://doi.org/10.1007/s40614-014-0017-y

De Leo, G., \& Leroy, G. (2008). Smartphones to facilitate communication and improve social skills of children with severe autism spectrum disorder. Proceedings of the 7th International Conference on Interaction Design and Children - IDC '08, 45. http://doi.org/10.1145/1463689.1463715

Delarosa, E., Horner, S., Eisenberg, C., Ball, L., Renzoni, A. M., \& Ryan, S. E. (2012). Family impact of assistive technology scale: development of a measurement scale for parents of children with complex communication needs. Augmentative and Alternative Communication, 28(3), 171-80. http://doi.org/10.3109/07434618.2012.704525

Dunn, M. E., Burbine, T., Bowers, C. a., \& Tantleff-Dunn, S. (2001). Moderators of stress in parents of children with autism. Community Mental Health Journal, 37(1), 39-52. http://doi.org/10.1023/A:1026592305436 
Fage, C., Pommereau, L., Consel, C., Balland, É., \& Sauzéon, H. (2014). Tablet-based activity schedule for children with autism in mainstream environment. Proceedings of the 16th International ACM SIGACCESS Conference on Computers \& Accessibility, 145-152. http://doi.org/10.1145/2661334.2661369

Hidalgo-Mazzei, D., Mateu, A., Reinares, M., Undurraga, J., Bonnin, C. del M., SanchezMoreno, J., ... Colom, F. (2015). Self-monitoring and psychoeducation in bipolar patients with a smart-phone application (SIMPLe) project: design, development and studies protocols. BMC Psychiatry, 15(1), 52. http://doi.org/10.1186/s 12888-015-0437-6

Kakihara, M. (2014). Grasping a global view of smartphone diffusion : An analysis from a global smartphone study. In International Conference on Mobile Business (p. 11). Retrieved from http://aisel.aisnet.org/icmb2014

Keenan, M., Dillenburger, K., Doherty, A., Byrne, T., \& Gallagher, S. (2007). Meeting the needs of families living with chldren diagnosed with autism spectrum disorder.

Children, Adolescent \& Family Services; 1096. Retrieved from http://lenus.ie/hse/handle/10147/45853

Lai, J. K. Y., \& Weiss, J. A. (2017). Priority service needs and receipt across the lifespan for individuals with autism spectrum disorder. Autism Research, 10(8), 1436-1447. http://doi.org/10.1002/aur.1786

Lathia, N., Pejovic, V., Rachuri, K. K., Mascolo, C., Musolesi, M., \& Rentfrow, P. J. (2013). Smartphones for large-scale behaviour change interventions. IEEE Pervasive Computing, 12(3), 66-73. http://doi.org/10.1109/MPRV.2013.56

Liu, G. Z., Wu, N. W., \& Chen, Y. W. (2013). Identifying emerging trends for implementing learning technology in special education: A state-of-the-art review of selected articles published in 2008-2012. Research in Developmental Disabilities, 34(10), 3618-3628. http://doi.org/10.1016/j.ridd.2013.07.007 
McDowell, C., Hardy, N., \& Smyth, S. (2017). Teaching Children with Autism to Use Cell Phones to Seek Assistance when Lost. Psychology \& Psychological Research International Journal, 2(5), 1-4.

Mechling, L. C. (2007). Assistive technology as a self-management tool for prompting students with intellectual disabilities to initiate and complete daily tasks : A literature review. Education and Training in Developmental Disabilities, 42(September), 252269.

Mechling, L. C., Gast, D. L., \& Krupa, K. (2007). Impact of SMART board technology: an investigation of sight word reading and observational learning. Journal of Autism and Developmental Disorders, 37(10), 1869-82. http://doi.org/10.1007/s10803-007-0361-9

Mechling, L. C., \& Seid, N. H. (2011). Use of a hand-held personal digital assistant (PDA) to self-prompt pedestrian travel by young adults with moderate intellectual disabilities. Education and Training in Autism and Developmental Disabilities, 46(2), 220-237.

Mintz, J. (2013). Additional key factors mediating the use of a mobile technology tool designed to develop social and life skills in children with autism spectrum disorders: evaluation of the 2nd HANDS prototype. Computers and Education, 63, 17-24. http://doi.org/10.1016/j.compedu.2012.11.006

Mulvaney, S. A., Ho, Y.-X., Cala, C. M., Chen, Q., Nian, H., Patterson, B. L., \& Johnson, K. B. (2013). Assessing adolescent asthma symptoms and adherence using mobile phones. Journal of Medical Internet Research, 15(7), e141. http://doi.org/10.2196/jmir.2413

Orinstein, A. J., Helt, M., Troyb, E., Tyson, K. E., Barton, M. L., Eigsti, I.-M., ... Fein, D. A. (2014). Intervention for optimal outcome in children and adolescents with a history of autism. Journal of Developmental and Behavioral Pediatrics : JDBP, 35(4), 247-56. http://doi.org/10.1097/DBP.0000000000000037

Parsons, S., \& Cobb, S. (2011). State-of-the-art of virtual reality technologies for children on 
the autism spectrum. European Journal of Special Needs Education, 26(March 2015), 355-366. http://doi.org/10.1080/08856257.2011.593831

Pituch, K. A., Green, V. A., Didden, R., Lang, R., O’Reilly, M. F., Lancioni, G. E., \& Sigafoos, J. (2011). Parent reported treatment priorities for children with autism spectrum disorders. Research in Autism Spectrum Disorders, 5(1), 135-143. http://doi.org/10.1016/j.rasd.2010.03.003

Ploog, B. O., Scharf, A., Nelson, D., \& Brooks, P. J. (2013). Use of computer-assisted technologies (CAT) to enhance social, communicative, and language development in children with autism spectrum disorders. Journal of Autism and Developmental Disorders, 43(2), 301-322. http://doi.org/10.1007/s10803-012-1571-3

Putnam, C., \& Chong, L. (2008). Software and technologies designed for people with autism: What do users want? Proceedings of the 10th International ACM SIGACCESS Conference on Computers and Accessibility, 8. http://doi.org/10.1145/1414471.1414475

Raento, M., Oulasvirta, A., \& Eagle, N. (2009). Smartphones: An emerging tool for social scientists. Sociological Methods \& Research, 37(3), 426-454. http://doi.org/10.1177/0049124108330005

Smith, A., McGeeney, K., Duggan, M., Rainie, L., \& Keeter, S. (2015). U.S. smartphone use in 2015. Pew Research Centre. Retrieved from 202.419.4372

Sreckovic, M. A., Brunsting, N. C., \& Able, H. (2014). Victimization of students with autism spectrum disorder: A review of prevalence and risk factors. Research in Autism Spectrum Disorders, 8(9), 1155-1172. http://doi.org/10.1016/j.rasd.2014.06.004

Virnes, M., Kärnä, E., \& Vellonen, V. (2015). Review of research on children with autism spectrum disorder and the use of technology. Journal of Special Education Technology JSET, 30(1). http://doi.org/10.1177/016264341503000102

Vohra, R., Madhavan, S., Sambamoorthi, U., \& St Peter, C. (2013). Access to services, 
quality of care, and family impact for children with autism, other developmental disabilities, and other mental health conditions. Autism : The International Journal of Research and Practice, 0, 1-12. http://doi.org/10.1177/1362361313512902 WHO. (2016). Improving access to assistive technology (Vol. EB139/4). Geneva.

\section{TABLES}

Table. 1

Percentage of Respondent Ratings on Five Experience Related Dimensions of AT

\begin{tabular}{lccccc} 
& Very good & Good & Fair & Poor & Very Poor \\
\hline Effectiveness & 50 & 24 & 21 & 2 & 2 \\
Ease of use & 55 & 31 & 7 & 7 & 0 \\
Needs driven & 36 & 33 & 24 & 5 & 2 \\
Accessibility & 52 & 33 & 10 & 2 & 2 \\
Cost effective & 26 & 36 & 24 & 14 & 0
\end{tabular}




\section{FIGURES}

Figure 1 Top

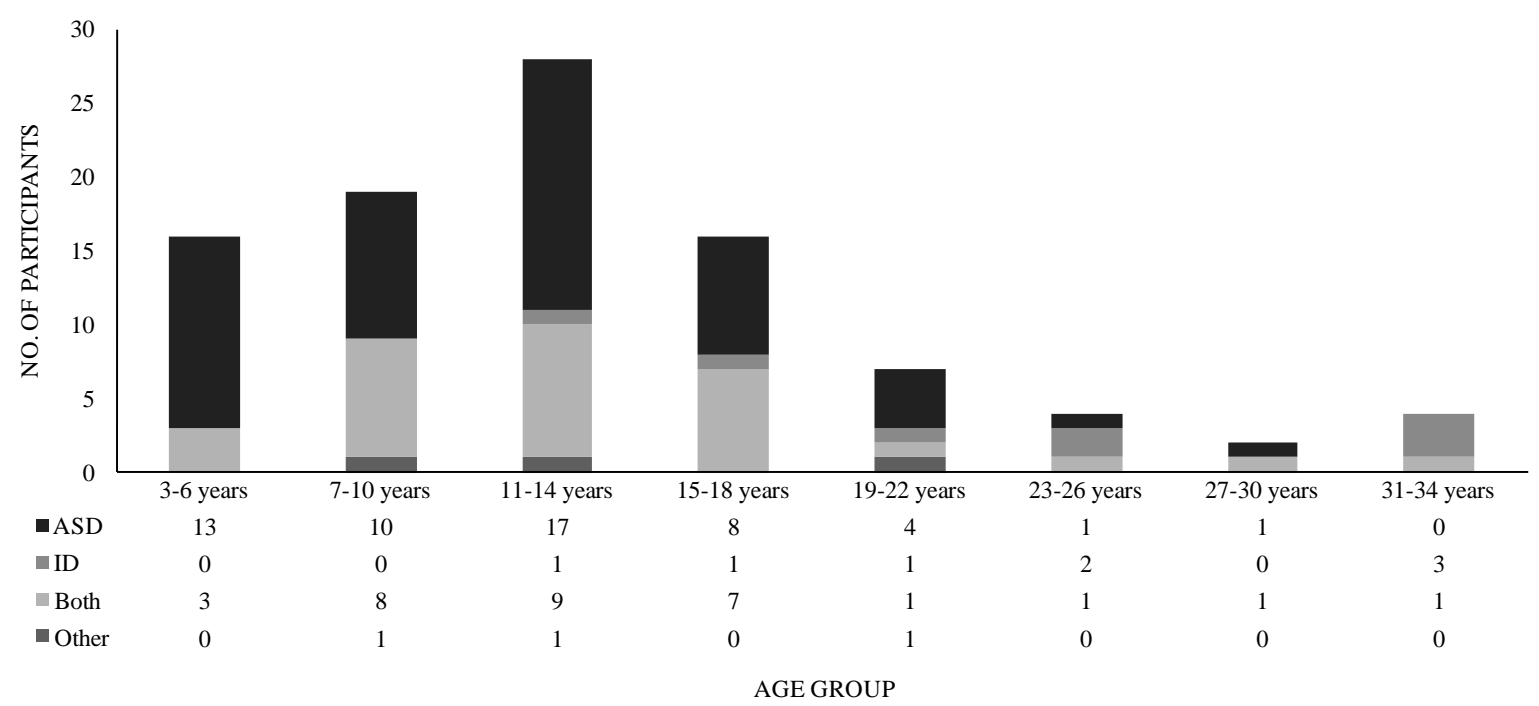


Figure Caption

Figure 1. Distribution of focus-individuals by age group and diagnosis. 


\begin{tabular}{|c|c|}
\hline \multicolumn{2}{|c|}{ Appendix A } \\
\hline & Survey questions \\
\hline Q1 & What is the diagnosis of the person this survey relates to? \\
\hline Q2 & How old is this person? \\
\hline Q3 & Gender? \\
\hline Q4 & What is your relationship to the person in question? \\
\hline Q5 & What type of service does this person currently access? \\
\hline Q6 & $\begin{array}{l}\text { How much help/support does this person currently need to manage their } \\
\text { time or day-to-day activities? }\end{array}$ \\
\hline Q7 & How would you rate this person's level of independence? \\
\hline Q8 & $\begin{array}{l}\text { How highly do you rate this person's ability to manage their own time and } \\
\text { daily activities? }\end{array}$ \\
\hline Q9 & $\begin{array}{l}\text { In your opinion, what is the biggest barrier to independence for this } \\
\text { person? }\end{array}$ \\
\hline Q10 & $\begin{array}{l}\text { Does this person currently use an assistive technology or have they used } \\
\text { an assistive technology in the past? } \\
\text { NOTE: Assistive technology can be any form of technology (e.g., tablet device, smartphone, computer, wearable, } \\
\text { device or app), piece of equipment, or system that helps a person function more independently in their daily } \\
\text { life, manage their own behaviour, communicate better, or learn new skills and information. }\end{array}$ \\
\hline Q11 & $\begin{array}{l}\text { If yes, how many forms of assistive technology have they used, or are } \\
\text { currently using? }\end{array}$ \\
\hline Q12 & $\begin{array}{l}\text { What is/was the main purpose of this assistive technology? If the } \\
\text { technology had/has multiple purposes, please select those that apply. }\end{array}$ \\
\hline Q13 & What is/was the assistive technology accessed on? \\
\hline Q14 & How would you rate this assistive technology? \\
\hline Q15 & $\begin{array}{l}\text { If you were on the design team, what would this assistive technology be } \\
\text { able to do for the person with ASD/ID, that it currently does not or did not } \\
\text { do? }\end{array}$ \\
\hline Q16 & Does this person have access to a smartphone? \\
\hline Q17 & How would you rate their ability to use the smartphone? \\
\hline Q18 & What do they use their smartphone for? \\
\hline Q19 & $\begin{array}{l}\text { How strongly do you agree with the statement "Today smartphones are } \\
\text { integrated with most people's daily lives". }\end{array}$ \\
\hline Q20 & $\begin{array}{l}\text { Does this person's parent/guardian/caregiver have some experience of } \\
\text { using a smartphone? }\end{array}$ \\
\hline Q21 & $\begin{array}{l}\text { In your opinion, what area (s) would benefit most from a behavioural } \\
\text { intervention that use smartphone technology? } \\
\text { (i.e., based on the principles of Applied Behavioural Analysis; ABA) }\end{array}$ \\
\hline $\begin{array}{l}\text { Excluded } \\
\text { Q22 }\end{array}$ & $\begin{array}{l}\text { What activities would this person typically take part in throughout the } \\
\text { day? Please briefly list them. }\end{array}$ \\
\hline $\begin{array}{l}\text { Excluded } \\
\text { Q23 }\end{array}$ & What is the name (brand name) of this assistive technology? \\
\hline
\end{tabular}

